\title{
"How Do I Bring Diversity?" Race and Class in the College Admissions Essay
}

\author{
Anna Kirkland Ben B. Hansen
}

In the first systematic study of what college applicants invoke when required to submit a diversity essay, we revisit many settled assumptions on both the left and the right about how such an essay would operate after Grutter and Gratz as well as after the passage of anti-affirmative action ballot initiatives. Our data are a sample of 176 diversity essays submitted to the University of Michigan in the immediate aftermath of the University's Supreme Court win, analyzed both qualitatively and quantitatively with special attention to the differences that the essay writer's race and class position make. We find that in many respects the essays are similar when written by applicants from similar backgrounds but different races, and that conservative critics were wrong to assume the essay would function simply as a way of announcing oneself as an under-the-table affirmative action candidate. Rather than suggesting a straightforward lineup of advantage and disadvantage, we suggest rather that the essay is a vehicle for the youngest generation of citizens to both receive and send back a new conception of difference that has some essentializing elements but overall is turning in a postracial, cosmopolitan direction.

\section{Introduction: "Uh, how DO I bring diversity?"}

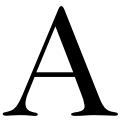

college applicant posted to an advice Web site for help writing her diversity essay with the subject line "Uh, how DO I bring diversity?" She explains that she is "just a regular Asian girl who plays piano and tennis and loves math and science" and really "pretty boring." Whatever diversity is, she is fairly uncertain she

The authors wish to thank the Office of Undergraduate Admissions at the University of Michigan, the Office of General Counsel, the College Board, ACT Inc., the National Science Foundation (Grant\#SES-0753164), the National Center for Institutional Diversity, the Institute for Research on Women and Gender, and the Undergraduate Research Opportunity Program for their considerable cooperation in assembling the data for this project and for providing funding. We received very helpful feedback along the way from audiences at the University of Michigan Law School, the Michigan Center for Political Studies Workshop on Democratic Politics, and the University of Connecticut School of Law, and especially from Ellen Berrey, Anthony Chen, Daniel Lipson, and three anonymous reviewers. Jessica Kosteva provided valuable research assistance. Please direct correspondence to Anna Kirkland, 204 South State Street, Ann Arbor, MI 48109-1290; e-mail: akirklan@umich.edu. 
would be able to contribute to it. A member with the username "ADad" points out that being a woman interested in science would bring diversity (even if it is, as she put it, "so Asian"). Another with the username "M's Mom" reassures her that "Diversity isn't just race or culture - it can be your love of science fiction, your ability to distinguish between all the varieties of pasta, your killer parchesi [sic] game, [or] your Pied Piper-like rapport with small kids" (College Confidential 2008: http://talk.collegeconfidential.com/collegeessays/463195-uh-how-do-i-bring-diversity.html).

This small exchange is revealing in many ways. It demonstrates uncertainty about the meaning of diversity but also supplies the outlines of an answer to what diversity has come to mean for the younger generation. Does bringing diversity mean having a dramatic or unusual personal story? Does it mean being an underrepresented minority, like a woman in the sciences or perhaps black, Latino, or Native American? If that is what it means, is the diversity essay simply a prompt for applicants to reveal their eligibility for affirmative action? What then are the majority of applicants supposed to write about? We see why this young woman does not see how she would contribute: She does not feel unusual, and she knows she is not a sought-after member of an underrepresented minority group. If the essay prompt she must address ("How would you as an individual bring diversity?") is to be taken seriously, however, it must mean that every individual can contribute to diversity, not just those formerly named as affirmative action targets. Thus we come to "M's Mom"'s reassurance that being able to name all the different shapes of pasta surely counts as bringing diversity.

In this study, we seize upon a unique moment when applicants write the required "diversity essay" for the University of Michigan undergraduate application. We present the first systematic empirical study of what diversity essays actually say. We employ propensity score matching to draw a stratified sample of diversity essays from the 2003-2004 application cycle to analyze for accounts of diversity as well as to match those accounts to the essay writers' race and class background. When applicants formulate an answer to the Michigan essay questions about diversity, they are forced to articulate what diversity is (at least implicitly) and to position themselves in relation to it. Naturally, they do so in a way that they hope will help them win admission to a prestigious university, but we contend that this moment is more than mere posturing. They are learning how to talk about pluralism, difference, groups, and individuals, and to imagine themselves in such a context. We are interested in the operation of diversity talk as ideology and culture, so the fact that it must be posed and presented in certain stylized ways does not disrupt its power as a political message (both sent to the applicant by posing the question and sent back by the essayist). 
We are particularly interested in the rhetorical poses that applicants from different racial, ethnic, and class backgrounds adopt in their essays and what the implications of those poses might be. Is the diversity essay a chance for members of "Generation Me" to extol their own personal uniqueness and specialness, with diversity totally stripped of any connection to racial inequalities or group identities? Is diversity really as vacuous as knowing farfalle from fusilli? Do young people imagine that diversity is good for getting jobs in the global economy, reflecting an instrumental, skill-driven conception of diversity? Do white applicants from all-white suburbs recognize the "lack of diversity" language as a prompt for them? Will minority students see either option as a prompt to make themselves available for recognition by counselors eager to practice old-fashioned affirmative action? If minority applicants excise their racial identity from their essays, what if "the life story of many people - particularly with regard to describing disadvantage - simply does not make sense without reference to race," as Carbado and Harris point out in a recent piece on the problem of color-blind admissions and the personal statement (2008:1148)? Carbado and Harris worry that minority applicants who try to write their essays without any reference to race will be "disadvantaged because their lives will be unintelligible to admissions officials and unrecognizable to themselves" (2008:1148). Will wealthy whites write about global diversity encountered on expensive vacations? How will low-income students understand their class position-as a great angle on diversity? Or does lower class status mean that these applicants are not privy to insider knowledge about how to play the diversity game? And finally, what does the diversity essay $d_{0}$ in this moment of instruction about how to enter adult life? What do these young people do with it? How are these applicants bringing new knowledge into the institution, and what are the implications of their formulations?

The diversity essay is, among many things, a written record of young citizens' active interpretations of a crucial legal and political concept. It represents a case of what Edelman terms the endogeneity of law, in which what the law means is culturally produced within an organization as well as imposed from the outside (2005). More specifically, the institutional location of the essay and its organizational raison d'être most obviously illustrate what Lipson calls the "diversity consensus" among high-level university administrators and admissions officials - that is, the dedication to racial diversity as the core meaning of diversity and a commitment to use diversity as a legal way of continuing race-based affirmative action policies (2007). ${ }^{1}$ Most neoinstitutionalist work on law and

${ }^{1}$ Michigan voters approved the Michigan Civil Rights Initiative on November 7 , 2006, which banned the use of "race, sex, color, ethnicity, or national origin" in public 
organizations has addressed how businesses respond to antidiscrimination mandates and create legal norms, where the primary actors are employees in positions similar to admissions officials in a university (Edelman 1992, 2005; Edelman, Erlanger, et al. 1993; Kalev et al. 2006; Kelly \& Dobbin 1998). The applicants are easily overlooked contributors to the constitutive meaning of diversity in the law, because they do not make organizational policy and it is easy to dismiss them as simply parroting what they think they are supposed to say. But it is undeniable that the students themselves are a continually changing new population that the essay explicitly invites to weigh in on the meaning of diversity each year. The essay is an institutionalized vehicle for their expression, and its very presence on the application as a requirement sends a strong message. Of course outside lawsuits, the Supreme Court, and other cultural forces like multiculturalism pushed along the changes at the University of Michigan (Berrey, forthcoming). And of course the applicants want to get into a competitive university, not ruminate on legal concepts. But such a directly addressed moment of consideration must have constitutive meaning. We argue that the applicants themselves have indeed generated new meanings for diversity quite unlike some conceptions emphasized in the University's public messaging. Moreover, these new meanings are far from determined by the applicants' own racial and class positions, such that the deployment of diversity cannot do what many commentators on both the right and the left presumed it would do.

As is well known, the University of Michigan was the defendant in two high-profile anti-affirmative action lawsuits and ultimately prevailed in the Supreme Court's rulings in June 2003. ${ }^{2}$ Grutter $v$. Bollinger (2003) and Gratz v. Bollinger (2003) held that diversity could be a compelling state interest justifying the use of race as one factor in law school and undergraduate admissions, but insisted that an individualized system of evaluation of each applicant replace the point system that the Office of Undergraduate Admissions (OUA) had been using to quantify the benefit of membership in an underrepresented minority (URM) group (among many other factors). An August 2003 press release from the university promised "highly individualized review" in a "flexible" admission process. There would be a new diversity essay requirement to gain the "richest possible picture of the student's intellect, character and personal values" (Peterson 2003: n.p.). Applicants initially had to

education, employment, or contracting. The University of Michigan remains obligated to comply with federal antidiscrimination laws.

${ }^{2}$ The University prevailed in the sense that the Court affirmed diversity as a compelling state interest that would permit the use of race in narrowly tailored ways. The Law School's more individualized process was upheld under this standard, but the undergraduate admissions process had to be substantially redone. 
choose one of two prompts when writing this new required diversity essay: (1) "At the University of Michigan, we are committed to building an academically superb and widely diverse educational community. What would you as an individual bring to our campus community?" or (2) "Describe an experience you have had where cultural diversity - or lack thereof-has made a difference to you." (Our sample of essays is drawn from the first year of these questions.) The first is almost identical to the one that stymied our "regular Asian girl" above, while the second is notable both for the prompt about what sort of diversity to write about ("cultural") as well as for its hint that lack of diversity is a suitable essay topic. The essay prompt has changed since 2003 and may change yet again. ${ }^{3}$ On the current application, the applicant sees just one essay prompt:

"We know that diversity makes us a better university - better for learning, for teaching, and for conducting research." (U-M President Mary Sue Coleman)

Share an experience through which you have gained respect for intellectual, social, or cultural differences. Comment on how your personal experiences and achievements would contribute to the diversity of the University of Michigan.

Most educational, political science, economic, or sociological research on the effects of diversity looks at the student/citizen as an outcome, measuring changes in racial bias or levels of civic engagement, often by using a survey. Educational researchers have continued to study the question of diversity's effects in the college environment, with most evidence pointing toward modest positive effects of diversity - nearly always operationalized as racial and ethnic diversity - on reducing bias and helping students to gain other cognitive and interpersonal skills in preparation for life in a multicultural democracy (Denson 2009). Political scientists measure levels of racial and ethnic diversity in communities and classrooms, asking whether a diverse environment drives down solidarity or fosters more engagement (Campbell 2007; Oliver 2001; Putnam 2007). These political science researchers tend to be more pessimistic about what diversity means in citizens' lives, finding that it can provoke racism and undermine preconditions for civic engagement at the community level. Educational researchers obtain more favorable results with the college population, though much work emphasizes that there are many influences on how

${ }^{3}$ Michigan has applied to join the Common Application (which does not have a mandatory diversity essay), and officials are considering what might go into a supplementary section should the request be approved (Personal communication, Erica Sanders, Director of Recruitment and Operations at the Office of Undergraduate Admissions, 4 Dec. 2009). 
students understand campus diversity and that students' own motivation to engage is often of primary importance (Pascarella et al. 1996). These studies necessarily presume to know what diversity is; that is, they stipulate it (racial composition, for example, or a pre-set "openness to diversity" questionnaire) and then try to determine its effects. Some qualitative work allows more openness for student interviewees to describe how they experience diversity. One interview study of 103 California undergraduates found that black and Latino students were more likely to invoke the sense of belonging that racial and ethnic diversity conferred (Santos et al. 2007). Other frequently arising themes were gaining multicultural competence, evolving in one's own ethnic identity, feeling connection across ethnic groups, and politicizing one's ethnic identity. Negative characterizations of diversity came out, too: discomfort, discrimination, tension, and segregation. Notably, even this rare qualitative study specifically framed diversity as primarily about race and ethnicity, and the students were told before the interviews that they would be talking about "ethnic identity development" (2007:106). The Michigan essay does its own framing, too, of course, but because it is more open-ended, this study allows us to capture those essays that simply miss the cue entirely and do not refer to anything about diversity at all.

This study examines the essays only as applicants write them, not as they are read in the Michigan admissions office. While admissions officers are certainly a primary locus of organizational culture, in this context we found them to be highly constrained by the publicity and litigation ongoing at Michigan. Previous work attempting to "get inside" the admissions process notes that many institutions are quite reluctant to grant access to admissions processes (Steinberg 2003, an unusually candid study of the 1999 Wesleyan process; Stevens 2007, a scholarly study with anonymity given to the institution). Lipson (2007) garnered interviews with officials at other comparable universities in his work on affirmative action, but we had reason to believe that the uniquely high scrutiny of the Michigan process would render it very difficult to gather evidence on questions like whether admissions officials try to use the essay as a race proxy. Berrey's (2009) research on Michigan specifically describes a distant, canned interview with a high-up admissions official consisting of a PowerPoint summary of diversity talking points and emphasizes the highly disciplined messaging in the face of the 2003 litigation. We originally initiated this request for a sample of essays in early 2005, a time when Michigan faced a considerable threat of litigation from conservative groups eager to prove that the university was still using race illegally. Obtaining the essays took more than two years of cooperation with the General Counsel's Office, the Institutional Review Board, and the Office of Undergraduate Admissions. 


\section{Converging on Diversity: The Legal, Corporate, and Educational Routes}

Untangling an exact genealogy of the idea of diversity is beyond the scope of this article, but it is fascinating to note that the idea became dominant in several institutional fields in just a few decades. The legal story of diversity jurisprudence most clearly begins with the 1978 Supreme Court decision in Regents of the University of California v. Bakke, which banned racial balancing, remedying societal discrimination, and increasing the number of doctors who might serve minority communities as possible compelling governmental interests for the state medical school. High-level judicial hostility to affirmative action's basic aims meant that the diversity rationale evolved as an alternative, not as an independently robust jurisprudential concept. Besides remedying past discrimination, diversity in the student body was left standing as a permissible justification for using race in admissions because of the need for wide pursuit of intellectual goals in a university setting. Justice Lewis Powell's single opinion for the plurality in Bakke extolled the Harvard system for its individualized assessment of each applicant, in which "blacks ... musicians, football players, physicists [and] Californians" would all be considered for their unique traits (Regents of the University of California v. Bakke 1978: 316). In the intervening years between Bakke and Grutter and Gratz, scholars set to work analyzing what effects diversity (overwhelmingly conceived of as racial diversity) has in learning environments so that by the time of the lawsuits, Michigan's own faculty had assembled research to defend the idea that having reasonably large racial and ethnic variation in the student body provided an educational benefit to all students (Gurin, Dey, et al. 2003; Gurin, Lehman, et al. 2004a; Gurin, Nagda, et al. 2004b; Hurtado et al. 2003).

The crucial concept at issue in the 2003 cases, which finally got around to testing the diversity rationale from Bakke, was "critical mass" and its capacity to produce educational benefits. Was getting a critical mass of URM students (as Michigan claimed it needed) just a new way of describing an unconstitutional quota system, or could it be justified in more individualized terms? Simply wanting a certain number of students from underrepresented groups as a matter of distributive justice would be illegal. Similarly, even though research shows that having a critical mass of minority students helps those minority students succeed academically and socially in college (Denson 2009), an aim of assistance to them alone would also be unconstitutionally redistributionist. Justice Sandra Day O'Connor concluded in her Grutter opinion for the majority that members of a diverse learning community meet 
many different kinds of people from various groups, thereby defeating group-based stereotypes as well as the problem of minority group members having to serve as spokespeople to whites for their entire race (Grutter v. Bollinger 2003:326-7). Minority students are supposed to reveal how they are different from each other, thus undercutting the idea that racial membership means something thick about one's identity, yet it is still desirable to have certain numbers of students representing certain racial groups so that those individual differences can be revealed. One of us has elsewhere argued that this is an odd account of the meaning of racial difference, where it must be represented but only so that its meaning can be undercut (Kirkland 2008:64-71). It also depends on what the students actually think, do, and say on campus. The ideal outcome would be that individual student exchanges undercut pernicious group stereotypes (rather than, say, support them through superficial, tense, or segregated exchanges). The crucial point is that Justice O'Connor's majority opinion set up an account of why groups matter that rules out their mattering for one primary reason: because groups per se should be represented so that group members can share that identity with others. As we demonstrate below, this presumptively unconstitutional view of racial groups pops up regularly in the diversity essays.

Corporate diversity rhetoric and practices also began from a concern with race, ethnicity, and nationality in the workforce but quickly widened to characterize diversity as an organizational resource rooted in various employee skills and backgrounds that must be effectively managed. Sociologists and organizational theorists have traced the corporate path of diversity from a 1987 publication called Workforce 2000, which heralded the explosive growth of minorities and immigrants in the U.S. workforce (erroneously overstating it, as it turned out, but that point of fact was soon lost) (Edelman, Fuller, et al. 2001; Kelly \& Dobbin 1998). As Kelly and Dobbin explain, once organizations instituted antidiscrimination compliance offices, managers became entrenched in the organizations and were able to retheorize diversity as good for business, in effect displacing more contentious policies like affirmative action while maintaining similar practices like targeted mentoring, diversity training, and holding managers accountable for meeting diversity goals (1998:978). While the categories salient in antidiscrimination law remained highly prominent, corporate diversity management took the same adaptive, individualized turn that the legal concept of diversity took. Hallmark and Westinghouse soon included such traits as "lifestyle," "position within the organization," and "culture" in their definitions of diversity, aiming to "mix quiet with talky people, electrical engineers with software and quality-assurance engineers" (Edelman, Fuller, et al. 2001: 
1617). As Berrey's (forthcoming) in-depth study of the University of Michigan's evolving approach to diversity from 1965 to 2005 shows, university officials downplayed the goal of increased numbers of minority students in response to the legal environment but also as a marketing strategy to present the university as a place where white students could have interesting encounters with difference. By the 1980s, Berrey (forthcoming) shows, Michigan had developed a racialized and ambiguous orthodoxy of diversity in which race was "the modal category" in a list of what counted as diversity but was simultaneously downplayed. The latest version of the Michigan diversity essay perfectly exemplifies a distillation of all these trends combined to meet the needs of a large elite public university. It does not mention race at all. It begins with the claim that diversity is beneficial (as opposed to balkanizing or contentious), then prompts the applicant to think of diversity as "intellectual, social, or cultural differences." The applicant's contribution to diversity is not to represent group membership, but rather to bring "personal experiences and achievements."

Given the particular historical context and suggestions from past research, what would we expect these essays to say? We expected that given the salient context from the Court rulings in the summer before these students applied, they would conceptualize diversity as racial or ethnic diversity first and foremost. We hypothesized that minority students would announce their status, while white students would have a more awkward task, perhaps taking the angle of admitting their lack of diversity or focusing on more personal or intellectual traits (as the conservative intellectual diversity movement suggests). For minority applicants, past research suggests they might describe the ways a diverse environment creates ethnic pride and solidarity but can also promote tension across groups. Because past research does not separate by class as we do here, we had no way of knowing if some of these understandings of diversity might vary by applicant income context. It seemed likely that it would, given the ways that diversity discourses have become so bound up with corporate and organizational aims.

\section{Methodologies}

We employed a multimethod approach to study what exactly is going on with the diversity essays, to detect variation, and to assess the wider cultural context. We sampled essays from one application cycle, analyzed their themes, surveyed popular coaching resources and other institutions' essay questions, and conducted a follow-up focus group to probe more deeply into students' approaches to the 
diversity essay as well as current conceptions of diversity. Our sampling procedure allows us to explain what is in the essays in a way that is generalizable to the whole applicant pool in that year, but more important, it allows us to isolate whether the writers' racial identity or class position explains what essay themes they invokes. So that our data would serve all of these aims simultaneously-describing the overall applicant pool, revealing classbased trends, and helping to isolate the contribution of race per se-we engineered a novel sampling procedure combining state-of-the-art techniques from disparate areas of statistics.

\section{Sampling Diversity Essays at Michigan}

Our primary data are 176 diversity essays written for admission to the University of Michigan for fall 2004, the admissions cycle right after the Supreme Court's June 2003 Grutter and Gratz decisions, sampled from the pool of all undergraduate applications. We deliberately chose this time period because of the heightened attention to diversity at Michigan, assuming that the context would prime applicants to think most deeply about the topic that year. The sample is a probability sample, specifically, a stratified cluster sample. Before drawing it, the population was divided into strata; within each stratum some applications were grouped into small artificial clusters, then applications and clusters of applications were selected at random from each stratum. Each application had some chance of being selected into the sample, although this chance varied by stratum and by whether the application belonged to a cluster. The sample design supports both generalizations to the total applicant pool (because we pulled representative samples randomly from the different strata) and precise and detailed adjusted comparisons between minority and nonminority applicants who vary by class position. ${ }^{4}$

First we divided the entire pool of applicants who applied to enroll in fall $2004(n=17,750)$ into three strata based on the socioeconomic status (SES) of the high school attended. We used income data gathered by the testing companies (ACT and SAT) for all test-takers at each school. Natural breaks in the income picture led to three basic typologies of schools that applicants came from: (1) Highly Affluent (at which the poorest quartile of ACT or SAT test-takers come from families making more than $\$ 60,000$, so that

4 "Minority" applicants are under-represented minority groups: blacks, Latinos, and Native Americans. The entire population of applicants $(\sim 18,000)$ was 6 percent black, 4 percent Latino, and 1 percent Native American, with the rest white or "no response." Whites, Asians/Asian Americans, and "no response" were initially grouped together, but after looking at the differences between whites and Asians/Asian Americans it became clear that the groups needed to be disaggregated. "No response" continued to be grouped with whites. 
75 percent or more of college-bound seniors have family incomes of at least that much); (2) Upper Middle Class with Variation (with the poorest quartile of test-takers families' earning between $\$ 30,000$ and $\$ 60,000$ ); and (3) Low Income (poorest quartile earning below $\$ 30,000) .{ }^{5}$ A Highly Affluent school might be a private school with some scholarship students, Upper Middle Class with Variation might be a prosperous and well-regarded public high school, and Low Income would define a public school located in an inner city or in an economically depressed rural area. Many attendees of Low Income schools are underrepresented minorities, but schools in Michigan's Upper Peninsula, which is nearly all white, would also be typical. We stratified on the 25 th percentile of reported income rather than the median reported income because schools varied more in 25th percentiles of reported income. It is helpful to bear in mind that students taking college admissions test such as the ACT or SAT are generally wealthier than students from the same high schools who did not take a college admissions test and that we are dealing only with test-takers, not the whole school population. This division helped isolate unusually rich and unusually poor schools: The top and bottom strata were the richest one-sixth and the poorest one-sixth of schools represented in the applicant pool, while the middle stratum captured everything in between. We then oversampled the top and the bottom strata, to heighten the chance that patterns determined by social position would be evident in our data. Given the saturation of a managerial conception of diversity since the 1990s, we wondered if being able to talk "diversity talk" might be an upper-class skill, perhaps transmitted by professional parents, travel opportunities, summer camps, and the like. Our sampling procedure made it possible to test this hypothesis.

Prior to sampling, we matched comparable minority and nonminority applicants within school SES strata, forming matched sets of applicants. Matching applications before rather than after sampling was a luxury made possible by our access to rich information about the sampling units at the stage of sample selection. In samples from human populations, data relevant to study questions are often available only for the sample, and only after it has been

${ }^{5}$ Individual-level SES data is present but was unreliable at this stage because the data comes from forms high school seniors fill out when they take the SAT and ACT and from what they wrote on the UM application. For example, on the UM application, 6 percent of applicants chose "don't know" and 30 percent did not give an answer about income. However, in the sample we can see for each essay what the writer answered to those questions and also what the writer gave as parental education. Twenty-nine of the 50 "no responses" to the income question list a parent with an advanced degree, for example, while another nine list a parent with at least a B.A. We suspect that more affluent applicants leave that blank, guessing that it will not help them to look more advantaged in the admissions process. 
selected. In this study the reverse was true: To maintain anonymity of the applicants, the OUA selected the sample for us, according to our instructions, releasing to us with the essays only a subset of the variables that had been used to match the applicants. Even had OUA been willing to release all of the matching variables, however, pairing applications within the broader applicant pool would still have been preferable to matching after sampling, because it allows for closer matches. As we did match prior to sampling, our sample selection procedure had to draw into the sample either none or all of the applicants in any matched set: In sampling terminology, the matched sets functioned as clusters.

Our construction of the clusters made use of techniques from causal modeling, namely propensity score matching (Rosenbaum \& Rubin 1983) and optimal full matching (Hansen \& Klopfer 2006; Rosenbaum 1991). Within each stratum, we sought to match underrepresented minority applicants with non-underrepresented (white, Asian/Asian American, and "no response") applicants who were otherwise comparable. To do this, we first calculated propensity scores using dozens of matching variables (both demographic and scholastic about the applicant as well as about all applicants from that high school) culled from applications and from the profiles of secondary schools that ETS and ACT market to college admissions offices. In order to match essay writers from very similar, perhaps identical high school contexts, we calculated Mahalanobis distances between potential matches from dummy variables encoding their high schools, the high school's county (for in-state applicants), and the high school's region of the country (for out-of-state applicants). By matching on these distances, we privileged matching within the same school or, failing that, within the same county or region. By also matching within propensity-score calipers, we ensured that minority applicants would not differ systematically from their matched counterparts on any of the dozens of matching variables. This combination of Mahalanobis and propensity scoring methods mirrors that of the celebrated study design in which propensity matching was introduced to statisticians, a pairing of men exposed in utero to phenobarbital to otherwise comparable but unexposed men which served to anchor an assessment of phenobarbital's effects on cognitive development (Reinisch et al. 1995; Rosenbaum \& Rubin 1985). There as here, matching focused investigator resources, training attention on a few hundred matched subjects selected from many thousands of otherwise eligible subjects at the same time that it identified similar individuals from within dissimilar groups.

With the use of more recent optimal matching methods (Hansen \& Klopfer 2006), we updated Rosenbaum and Rubin's method to permit the matching to be combined with probability sampling. 
Whereas they matched only in pairs, our optimal full matching routine generated clusters of from two to four individuals, permitting us to place many more applicants into matched clusters than pair matching would have done. In the highest and middle SES strata, the clusters included one minority student and from one to three majority students, and in the lowest SES stratum, clusters contained one majority student and as many as three minority students. In each stratum, all the underrepresented minority applicants were matched if there was a suitable match available. Many majority students eligible to be matched to some minority student, in contrast, were left unmatched. The total number of clusters formed was 1,620: from high SES schools, 200; from middle SES schools, 880; and 540 from the low SES schools. The clusters are not, of course, representative of the applicant pool specifically nor college students generally - they contain many more lower-income applicants. Those of our analyses that sought to reconstruct aspects of the applicant pool on the basis of our sample compensated for this nonrepresentativeness with appropriate weighting of clustered and nonclustered observations.

In each stratum, clusters and unmatched individuals were selected separately, as random systematic samples. That is, we lined up the clusters based first on the size of the cluster and also on a measure of how closely the clusters had been matched up and then sampled systematically after a random start. This process insured against a sample containing too many of the less successful matches, or too many small or large clusters. The final sample of 176 essays contains 20 clusters of applicants from Low Income schools, 15 clusters from Upper Middle Class with Variation schools, 15 clusters from the Highly Affluent schools, and 10 unmatched individuals from each stratum. For a population of nearly 18,000 , a sample of 176 essays may seem small. It is relatively common, however, for studies in other fields using this method of propensity score matching to have similar sample sizes (Reinisch et al. 1995). We gained a great deal of precision on certain items of interest such as race, class, and essay content using this mixed method and sampling process, and while we cannot deny that greater numbers of essays might have found more significant variables, we have confidence in the detailed comparisons we are able to make here. There is no personally identifying information for any applicant attached to the essays - only an identification number assigned by the OUA. We do, however, know which of the nine U.S. Census divisions the applicants are from, their race, sex, household income, parental education level, whether the parent is a single parent, whether they were matched within their high school or not and with whom, and the type of home town they came from (rural, small town, large city, etc.). We do not know the 
final admissions decision or whether the essay writer enrolled at Michigan.

\section{Capturing Themes: Characterizations, Encounters, and Observations}

Coding aimed to capture characterizations of diversity, the type of encounter with diversity the applicant described, and any characterizations the applicant offered for diversity. Each essay got three reads by a single coder (the first author, a white woman), who was blinded to any trait of the essay writer except for the randomly generated identification number. Coding was exclusive and exhaustive, and it also reflected the relative saturation of ideas within the essay on a numerical scale of $0-3(0=$ no mention of the concept, 1 = concept named or listed once, $2=$ concept discussed in at least part of the essay beyond a simple listing or naming, and $3=$ concept discussed as the major thrust of the essay). In any new theme that emerged and required coding, all previous essays were re-examined for that theme. One concept was coded as a binary (whether or not the essay mentioned anything about diversity at all), and we also coded which of the two essay options the student chose: the more individualistic one (I) or the one with an explicit prompt to write about the difference cultural diversity or the lack thereof makes (DD). Use of a blinded single coder (fairly common in smaller-scale qualitative analysis) combined with a fairly rigidly defined two-way rubric (both content and relative saturation) offered high internal consistency, though it was likely impossible to remove the constitutive effects of one's own racial and class position from the reading of these essays.

Twelve codes emerged for definitions of diversity: race/ethnicity, gender, religion, class, sexual orientation, disability, opinions, music and food (nearly always mentioned as a pair), culture, internationalism, small town sensibility, and individual uniqueness. We also coded whether or not the essay even mentioned anything that could be a conception of diversity at all, as a large chunk had no discussion or characterization at all. These were all highly uniform general character essays about the applicant's passion and drive to succeed. We found 12 contexts or sites of encounter with diversity: a new place, found in travel or moving; sports; friendship; high school environment; encounters with exchange students; life in the hometown; the workplace; volunteering; summer programs; being born into an immigrant family; having bicultural parents; and books and studying. And finally, we coded for 12 types of normative observations about diversity: that there is a lamentable lack of diversity in the applicant's life that he or she acknowledges; that the applicant yearns for diversity; that diversity 
efforts can be a sham; that diversity causes tension between groups or that it can coexist with segregation; that underneath all our diversity we really see true commonalities; that diversity means sharing one's identity with others (particularly when one is a URM); that experiencing diversity is character-shaping; that diverse education is necessary for the "real world"; that experiences with people of different backgrounds has shattered one's stereotypes; that diversity is important for dispelling isolation and prejudice; that diversity protects minorities from isolation in all-white environments; and that one sees the need for diversity because of having observed prejudice against others.

Because it is of obvious concern where applicants are getting their ideas about diversity, we also conducted an analysis of coaching materials about the diversity essay, in both online and book form. We gathered the most popular essay prep books based on Amazon sales rankings and conducted Google searches to see what online resources are readily available to an applicant wondering how to approach this essay. We had originally thought that the diversity question was a trend in college admissions and would appear on many applications, but after surveying both national research universities and smaller regional colleges and universities, it looks like the diversity question is not particularly common. Few other schools have one on their application, probably for a wide range of reasons. ${ }^{6}$ Its relative rarity also means that explicit coaching about how to write the diversity essay does not saturate the test prep market as much as we might suspect. As we discuss in more detail below, the most popular resources either do not mention anything particular to a diversity essay at all, or they echo "M's Mom"'s advice that diversity can be practically anything, not just race or ethnicity.

Another method for getting beyond the stylized moment of the application essay is to probe more deeply for students' reflections about their diversity essay after they have spent some time at Michigan. We conducted a follow-up focus group with eight Michigan juniors and seniors to ask them in-depth questions about some of the tensions emerging in the analysis, such as whether diversity is first and foremost about race or whether it means a wide array of individualized traits with race explicitly decentered. (We do not know the identity of the essay writers, so there is no way to follow up with them in particular.) The focus group, held in March 2009 (well after coding and matched analysis of the essays were

${ }^{6}$ Among these are probably that the admissions are not very competitive anyway; that the school is not as restricted in its approach to affirmative action because it is private and not covered by an anti-affirmative action ballot initiative, as Michigan is; that other essay topics are thought to be more suitable; or that the admissions office does not think the essay would be worth the resources necessary to have the staff to read them all. 
complete), lasted one hour and was captioned in real time. Participants were drawn from a pool of Michigan students who had been a part of the Undergraduate Research Opportunity Program (UROP) during their first or second years and were now in their third or fourth year (but two students were recruited more informally). UROP was at one time geared toward historically underrepresented students but has dropped that emphasis in recent years; however, the pool of students who were in the program is more racially and ethnically diverse than the college population generally. There were thus particularly motivated and thoughtful undergraduates, but the group was not otherwise particularly homogeneous on race, ethnicity, class, major field, or gender. The focus group data are admittedly quite limited because we cannot follow up with any essay writers themselves and because of the very small size and unrepresentative nature of the group. We nonetheless include some of these students' reflections because they do show some greater detail and maturation that helps put the essays in perspective.

\section{The Coaching Question}

Quite understandably, the question of what the diversity essay is a case of runs up against the coaching question: these essays are simply the product of a coaching process, are they not? It is widely accepted that college admissions have become so competitive that middle- and upper-class parents resort to anything they think will get their child an edge, including essay coaching or even writing their child's essay themselves. We have no way of knowing what kind of coaching, if any, the essay writers in the sample received. We did not have access to the content of expensive coaching. Our method here was simply to replicate what a moderately energetic applicant would find in books and online to help in writing the diversity essay. We searched on Amazon in early 2007 using terms like diversity essay and college essay and then analyzed the content of several titles consistently ranked as best-selling. Collections of sample essays seemed less helpful, and we focused more on finding explicit advice about how to frame a diversity essay. We also Googled similar terms, exploring the most obvious returned results on Web sites like http://www.CollegeConfidential.com.

On the one hand, it is possible that the essays are not the result of much explicit coaching because it would be possible to look for advice and not find it. Two of the most popular and widely available coaching books, How to Write a Winning College Application Essay (Mason 2000) and The New Rules of College Admissions (Kramer \& London 2006), do not have dedicated sections about the diversity essay. How to Write a Winning College Application Essay does not even 
have the word diversity in its index. Many essays did not read as though anyone had even helped the applicants hone what they were trying to say, let alone reveal evidence of coaching. Pitfalls like vagueness, clichés, recaps of the resume, claims of "passion," and lack of a clear point were extremely common, and a quick glance at free Web sites or a flip through almost any guidebook would have immediately pinpointed these errors. Only a handful of essays were sufficiently polished (evocative opening sentence, vivid narrative, forceful close putting the experience in a larger context) that we guessed they were coached or at least well edited by someone else. (The few like this that we checked later were all written by applicants with $\$ 100,000$ or more in annual family income, though for less than $\$ 20$ one can purchase any number of essay writing guides that give very good, and quite uniform, advice.)

On the other hand, however, there is a distinct message readily available in coaching sources that defines what we call the diversity hierarchy and explicitly coaches differently situated applicants about what to write. The diversity hierarchy encapsulates the shift over time that Berrey (forthcoming) describes, as diversity orthodoxy came to be a blend of past affirmative action practices covered over with individualistic and nonracialized references to culture, experiences, and interactions. Race is still the starting point, but these primary sources describe it as obvious and blasé. Great Application Essays for Business School (Bodine 2006:84; highly ranked in Amazon sales, so perhaps students would be exposed to it even though it is not aimed at high school students) tells readers exactly what the diversity hierarchy is (a hierarchy repeated in other sources as well). ${ }^{7}$ When brainstorming for the diversity essay, Bodine instructs students, "[s]tart with the narrow, conventional definitions of diversity-gender and ethnic background" (2006:85). If the applicant cannot write about either of those traits, the next move is to think of one's "socioeconomic, cultural, and geographic" diversity. Next, "atypical" hobbies might be a good source, and as a last resort, "tell your "normality' tale as engagingly and vividly as you can" (2006:85-6). The New Rules of College Admissions explains exactly what "M's Mom" knew: "Remember that diversity relates not only to ethnicity, but also to socioeconomic class, type of school experience (public, private, charter, homeschooling), family circumstances, extracurricular interests, and more" (Kramer \& London 2006:96). Kramer and London (2006:97) explain that "the idea of diversity doesn't need to be dramatic." If an applicant only speaks one language and was born

7 This book is an outlier in having a specific section ("Vive la difference: The Diversity Essay") dedicated to prepping this type of essay. We include it because it is so helpfully explicit. 
in the United States, they note that it may be enough that the applicant is from the Midwest but applying to an East Coast school. "Admissions officers want their school to represent not only a variety of ethnicities," they explain, "but also a range of experiences."

Great Application Essays for Business School explicitly notes that while "the word diversity still carries an affirmative action tinge," the essay is actually an invitation from admissions committees "to help them sculpt a class of maximum variety" (Bodine 2006:84; emphasis in original). That is, the college coaching presentation of diversity explains it in terms of the institution's goal of balancing the entering class with a wide variety of people. From this viewpoint, universities are organizations that absorb diversity language into pre-existing organizational goals, both to foster compliance with the law and to promote their own goals (Edelman, Fuller, et al. 2001). "Contrary to what you might think," The New Rules of College Admissions proclaims, "colleges to do not want an entire school of A students with 1600s on their SATs. How boring!" (Kramer \& London 2006:124). Because the market for books about how to get into college presumably includes millions of anxious students who do not meet these numerical criteria and their parents, this move to make numbers achievement flat and boring means that the service the book supplies-improving the parts of the application that are not already determined, like the essays - is all the more important. "As you have learned," the book continues, "college admissions committees are faced with the task of creating diverse communities, including students of various ethnicities, geographic backgrounds, athletic talents, political thoughts, favorite movies, religious beliefs, senses of humor, artistic abilities, and more. To do this, they have to learn as much as they can about the students applying to their school" (Kramer \& London 2006:124). The purpose of the diversity essay from this perspective is to assist in the organizational goal elite institutions have articulated in recent decades: achieving the balance of violin players, Southerners, and athletes that Justice Powell lauded as the Harvard method in the Bakke case. ${ }^{8}$ It should not be forgotten, however, that a primary motivation for introducing these subjective considerations of background and character in the 1920s was to exclude Jewish students from the Ivy League schools, where their rising numbers caused panic among the Protestant elite (Karabel 2005).

\section{Individualism and Racial Representationalism, or Snowflakes and War Movies}

The classic World War II movie brings together soldiers who each represent some discrete racial, ethnic, and geographic

\footnotetext{
${ }^{8}$ We thank an anonymous reviewer for making this important point.
} 
subgroup from American life in a fairly predictable fashion: the Jew from Brooklyn, the white Southerner, a boisterous Italian American, a Midwestern farm boy, and maybe even a Native American or a Latino from the West. The premise of "war movie" diversity is that each character is there to play a recognizable role: to fulfill his group's stereotype, in other words. This is what we call racial representationalism in the essays, or the sense that diversity is at its core about having minority students present on campus for certain reasons: to share their unique perspectives as racial minorities. It means an understanding of diversity that is predictable and group-based, but represented by individuals who then showcase their culture. The essayist is then writing about learning from or contributing to this array of difference. So diversity is experiential, but it depends on an interaction in which a person "acts out" his or her didactic role assigned by his or her identity trait and fulfills it for the group. For example, one woman wrote about her sports team's diversity.

We had players from different ethnicities (such as Thailand and Taiwan), religions (like Christianity and Judaism), not to mention from different places in the surrounding area. There was the deeply pious Jill, who continued to preach her Christian faith throughout the entire season, crazy Ashley from [town redacted] whose outrageous hair and clothes became an eyesore, the "snotty" [town redacted] girls, ghetto Michelle from [town redacted], who showed us all how to "booty dance," and finally the "hicks" from [town redacted]. ${ }^{9}$

The lesson, she concluded, was "to be more accepting of others, not judging them on color, race, or socioeconomic backgrounds." Another applicant wrote about listening and learning from friends he played basketball with. "For example, I might approach one of my black friends about his views on hip-hop culture or the war on terror. At the same time, I can act as a resource to them. As someone who is very passionate about understanding current events, they know that they can ask me about something, such as why the United States supports Israel."

When minority essay writers affirmatively identified themselves (and as we show below, not all of them did), it was common to talk about "bringing diversity" to the university as if they were well aware that diversity is about their presence on campus. One applicant reflected on a summer program for minorities interested in math and science careers at which he or she realized that "not only would I personally benefit from pursuing a career such as engineering, but I

\footnotetext{
${ }^{9}$ We have changed all the names here.
} 
would benefiting [sic] society as well ... [by] being an example to others." This theme is coded as "sharing one's identity."

Another explicitly representationalist theme is the idea that diversity creates comfort for minority applicants (coded as "protective of minorities"). Like the need for an officer corps that is not too different from the enlisted ranks (as U.S. military generals argued in their amicus brief in the Michigan affirmative action cases), the protective function comes from having minorities represented in reasonable numbers. One black essayist wrote that having "not only white but Latino, Asian, and Indian friends ... creates a very comfortable atmosphere for me." Praising the enrichment that he or she had gained from this tolerant and equal high school environment, the applicant wrote that " $[\mathrm{m}] \mathrm{y}$ school is a place in which one's background is not the issue but 'how am I going to get an A on the next math test?"' One Hispanic essay writer described trying to get into a Christmas tree lighting ceremony and being turned away by police. They were "the only Hispanics among the hundreds of Caucasian people ... [and] many of them looked at us, as if we were inferior." The same police officer waved another group through, leaving the essay writer to conclude that the treatment was racist. "That was one of the few occasions in my life where I regret not being in a more culturally diverse place," the applicant concluded. Diversity here means sufficient racial variation so that minorities do not feel like they stand out too much. It is simply visible, not experiential or interaction-based.

Both "bringing diversity" and "war movie" diversity are in some tension with the account of diversity that the Supreme Court found constitutionally acceptable in the Michigan affirmative action cases of 2003. ${ }^{10}$ There the challenge in upholding any role for race-consciousness in Michigan's programs was to show that the university did not look to racial minorities just as a bloc to be represented but rather as different individuals. The "critical mass" concept was differentiated from a brute quota by Justice O'Connor's embrace of the idea that only among a large enough group could it become clear that not all black students think alike, for example. The point for Justice O'Connor was to undercut representationalism through diversity. Getting a mass of minority students was not then a drive to increase representation (a constitutionally prohibited objective), but rather a mechanism to defeat the very notion of representation. But both "bringing diversity" and "war movie" diversity rely fairly heavily on easily recognizable group stereotypes in which a person's contribution to the group is

${ }^{10}$ The military leaders' brief implies a much more representationalist view of race than Grutter and Gratz have come to stand for. 
re-enacting those shared scripts about group identities (being black and knowing about hip-hop, being Jewish and supporting Israel).

Interestingly, the students in the focus group explicitly and self-consciously deconstructed representationalist understandings of race. They all acknowledged thinking and being told that the essay was meant to ferret out racial diversity in order for the university to practice affirmative action. One male student who identified as white and Hispanic talked about his cousin whom "everyone except for me basically told to write about being half Lebanese ... to kind of shove that in there so "well, this is how we can fulfill our race quota." "Yes, he is half Lebanese," the student continued, "but he is also a very unique person and I think that got lost." A white student recalled being "disturbed" by coaching in her high school that black students should write about their race ("because that's what's important about you and nothing else") while white students should write about "how we lacked diversity and we lacked any ethnic connection." One Hispanic woman had come to Michigan from Miami to escape the "flaunting" of ethnic difference there so she could just focus on her major in geology and oceanography. She countered representationalism with experiences: "Whenever people think of race and being different, it's like wow, you must have a different ideology, let's say if you're Asian you think completely different from someone who's Caucasian. But in reality it's more about, you know, what experiences you've had in life, who you have interacted with and stuff like that." Students noted complexities like biracial identities (feeling identified with one parent's ethnicity but not looking to others like they should belong) and being white-identified despite having a different ethnic background (as in the case of one woman adopted from Guatemala by a white family). They went into great detail about searching out a unique identity for themselves as they left their families of origin. Racial and ethnic difference was always salient, but never dominant and never essentialist or bluntly representationalist. Perhaps the dramatic differences between the essay content and the focus group discussion can be explained by the more thoughtful format, the quite different expectations of the moments, and these particular students' maturation after several years of enrollment. These students are also much more likely to be biracial, multiracial, or a URM because of the program database from which they were recruited. Even given this skew toward students who are not simply white-identified, it is clear that they experience blunt racial representationalism as minimizing and reductionist.

If representationalism in the essays essentialized race, another important theme erased it entirely. One essay writer put it perfectly: "All persons are diverse, that is, made up of distinct 
characteristics, qualities, and elements." She went on to describe being home-schooled and how that has made her a unique person. Another student wrote about his background "as an athlete, as a mathematician, as a naturalist, as a scientist." He conceded that "other people also have many experiences," but "no one else has exactly the same combination that I have." This "snowflake" account of diversity is universalizing and yet wholly individualized: No person is exactly the same as any other, so everyone is diverse. For everyone to be diverse, one seemingly similar person must still be unique compared to another seemingly similar person. A group composed entirely of white middle-aged men would still be diverse because all of them are unique. (Note that this diversity would not serve any of the signaling purposes that the uncomfortable minority students say they need, nor would it help the military diffuse the racial tensions borne of having an all-white officer corps.) One kind of diversity is not necessarily more meaningful than any other (say, being black in America versus being white).

From the perspective of someone who supports affirmative action for broad social justice purposes, this turn from race to individual differences is vacuous and impotent. Bell and Hartmann point out that this dynamic - in which race is the first and most obvious association with diversity but is also undercut in the next breath of anyone struggling to define it -is how diversity talk maintains social hierarchies (2007). A brief essay extolling the applicant's personal uniqueness can quickly grate on the nerves, to be sure, seeming to confirm all the worst one hears about "Generation Me" (but see Trzesniewski et al. 2008; Twenge 2006). However, the focus group discussion showed that some students were deeply engaged with developing a personal identity free from the overdetermination of imposed categories. It was clear that the Michigan students were genuinely wrangling with their contributions to a world in which one could to some extent choose what kind of relationship to have with race, religion, and ethnic heritage. Identifying as multiracial or multiethnic seemed to be a crucial part of such a perspective. Students emphasized their Native American or Latino roots on one parent's side and insisted on maintaining that identity despite having an appearance and last name that others read as white. This announcing and caretaking of their ethnic identity was critical to their conclusion that experience and interactions were core aspects of diversity. Of course, choosing one's relationship with one's individualized racial self-concept is a lot easier with a physical appearance that does not readily announce minority status. Some students will bear the burden of being an example of minority achievement much more heavily than others. Are some students ready to embrace a deconstructed, instrumental, cosmopolitan conception of diversity while others still see it as 
racially remedial and minority-focused? What explains the differences among diversity essays - the essay writer's own racial position, or something else?

\section{Does Essay Content Vary by Race or Class of the Applicant?}

The presence of these themes is interesting, but we also want to know their rates of occurrence and something about who tends to invoke them. Recall that our methodology was designed to show differences by racial group (whites/no response, Asians, Latino/ Hispanic, and black) and to highlight any remaining differences between those groups even as compared to otherwise similar applicants from the same or a nearby high school. The sample weights also make it possible to generalize from the 176 essays to the population of essays submitted that year. There are also white applicants in the sample who were not matched to anyone; however, they are part of the unadjusted total. The data presented in Tables 1 though 6 first describe the whole weighted sample ("unadjusted") and then present the matched results ("matched"). Because we want to see the difference that income stratum makes apart from race, we also present tables broken down by income cohort. Longer tables showing some more background information appear in the Appendix. Appendix Table A introduces all the coding themes and their relative rates of appearance for whites as compared to Asians and whites as compared to URMs (blacks and Latinos). (Some themes were very infrequently mentioned by anyone, were not significant under any analysis, and were removed from later tables.) Because Asians wrote essays differently from whites in some significant ways and because there were relatively few Asians in the sample, their essays cannot be simply folded in with white applicants'. Appendix Table B demonstrates how the matching made white and URM applicants statistically indiscernible.

Table 1. Differences in Characterizations of Diversity by Race of the Essay Writer

\begin{tabular}{lcccccc}
\hline & Whites & URMs & Difference & Whites & URMs & Difference \\
\hline Cultural diversity question & 0.44 & 0.58 & 0.14 & 0.56 & 0.58 & 0.01 \\
Individualistic question & 0.56 & 0.42 & -0.14 & 0.44 & 0.42 & -0.01 \\
Mentions diversity & 0.61 & 0.78 & 0.17 & 0.81 & 0.87 & 0.06 \\
Race/ethnicity & 0.22 & 0.77 & $0.55^{* * * * *}$ & 0.58 & 0.91 & $0.33^{*}$ \\
Class & 0.06 & 0.09 & 0.03 & 0.30 & 0.14 & -0.15 \\
Religion & 0.14 & 0.09 & -0.06 & 0.37 & 0.14 & $-0.23^{*}$ \\
Culture & 0.18 & 0.53 & $0.34^{* *}$ & 0.40 & 0.63 & $0.22^{+}$ \\
Opinions/viewpoints & 0.13 & 0.17 & 0.04 & 0.06 & 0.17 & 0.11 \\
Internationalism & 0.33 & 0.01 & $-0.32^{+}$ & 0.16 & 0.02 & -0.14 \\
Individual uniqueness & 0.04 & 0.03 & -0.01 & 0.23 & 0.02 & $-0.21^{+}$ \\
\hline
\end{tabular}

Notes: ${ }^{+} p<0.10 ; * p<0.05 ; * * p<0.01 ; * * * p<0.001$. 
Table 1 shows an unadjusted comparison on the left side and the matched comparisons on the right side. Interestingly, matching washes out some of the differences by race but not all. But first let us point out the starkest null finding here: Table 1 makes clear that there is no "affirmative action cueing" function of the diversity essay at Michigan in one obvious sense. There is no discernible difference by race between essay writers who "heard" the cue to talk about diversity and those who did not in either the whole weighted sample or the adjusted matched comparisons, nor does race explain anything about which essay an applicant selected. One might suspect that white students would be more likely to take the more individualistic option as an "out," thinking they had less to say. However, the analysis in Table 1 shows that this is not the case. (There is a slightly greater incidence of these essays being written by whites, but we cannot rule out that the difference is due to chance. The variations by race for which question the applicant selected are also not statistically significant.) Those essays that got a score of 0 for "mentions diversity" were general character essays explaining the applicant's personality traits, hobbies, or favorite sports activities (not as part of defining diversity). Thirty-nine essays out of 176 were thus not really diversity essays at all. These essays were, predictably, all responses to question one, the more individualistic prompt. Recall how the scant coaching literature on the diversity essay presents it as yet another "tell your personal story" essay. Not surprisingly, an essay prompt that puts race so far in the background is easily interpreted as just another college essay about individual achievements. Whatever purpose a diversity essay is supposed to achieve, then, in a relatively large subset of applicants it does not do anything different from the most generic essay prompt.

Carbado and Harris have argued that if there is pressure to write race-neutral essays, then those written by minority applicants will be disadvantaged by having a highly salient topic removed. ${ }^{11}$ They predict that those advantaged will be those who view their racial identity as "irrelevant or inessential" or simply do not mention it (Carbado \& Harris 2008:1148). Yet it is not clear that the diversity essay is understood in those terms at all - in fact, evidence from the focus group suggests that there is explicit coaching to mention one's race and that it is widely presumed that the essay is a way of announcing one's race. Even so, our data suggest that there is no racial pattern to the decision to discuss one's race in the first

11 Of course, applicants are not state actors and so the act of submitting an essay revealing one's race could not be a constitutional wrong. The problem would be if admissions officials did something unconstitutional with that racial information. It is not unconstitutional or a violation of Michigan law to gather racial information or to have it in the admissions file. 
place. In the whole sample, minority applicants are significantly more likely than whites to discuss diversity as race or ethnicity (and to a slightly lesser extent, culture) when they write about diversity in any sense. When matched with otherwise similar white counterparts, this difference is somewhat diminished but remains significant, suggesting that being a URM explains a tendency to focus more on race as an essay theme. White applicants in the whole sample are more likely to characterize diversity as globalism or internationalism, selecting topics such as world affairs or international travel, or simply arguing that diversity is instrumental in training future workers to be part of the globalized economy. This difference disappears after matching, however, suggesting that their URM counterparts who are otherwise similar and attend the same or a similar nearby school invoke those themes at the same rate.

Interestingly, another variation appears after matching that differentiates white applicants' essay topics from their URM counterparts: the greater invocation of diversity as everyone's individual uniqueness. Just as other sociological studies of diversity discourses would predict (Bell \& Hartmann 2007; Berrey 2009; Boli \& Elliott 2008; Edelman, Fuller, et al. 2001), these essays back into diversity as individualism by noting that every person is different in some way from every other one. Religion is also a significantly more popular among white applicants in the matched sample, though it is not clear why. Discussions of religion are quite varied in content, ranging from discussions of the student's own religious background to observations of anti-Muslim prejudice in the aftermath of the 9/11 attacks. Perhaps if one is less likely to write about race, religion seems like a good alternative axis of difference. When we specifically raised the question of religion as diversity in the focus group, the students responded that religion was especially salient for them because going off to college presented a decision point for whether to continue the religious practices of their families of origin, to stop religious practice, or to try another religion. However, none of the essays discussed religion in this way.

Other null findings are interesting here because they suggest that regardless of race (or below, income), there are some ways of talking about diversity that just do not resonate much in this context. There was a near-total lack of interest in writing about gender, sexual orientation, or disability as diversity (not presented on the table because only one or two essays mentioned these). Of course one can expect plenty of men and women at Michigan no matter what, but given the fact that women as a group (especially white women) have been very visible "diversity candidates" in the work world, their absence is notable here. Perhaps writing about being gay requires being out already, while disability may seem too 
stigmatizing (in the case of one's own learning disability) or too remote (if able-bodied students are largely segregated from their disabled counterparts in school or in friendships). Disability marks some of the most dramatic differences between people, but it has never really gained more than lip service from diversity rhetoric more broadly. Perhaps disability generates such significant fissures in group advantage and disadvantage (by income, employment status, and educational attainment) while at the same time provoking such awkwardness that it is not very brochure-ready. We might have also expected diversity as different viewpoints to be raised somewhat defensively by white applicants because it has been a touchstone of conservative movements like Horowitz's (2004) campaign for intellectual diversity on campuses. There was little sense of conservative purpose to these invocations, however, and they were relatively rare and more often made by URMs than whites (though not at rates distinguishable from chance variation).

Carbado and Harris are right to suggest that there is a "new racial preference" in personal statements, but it is not the simple suppression of one's race. It is more like a "new post-racial cosmopolitanism" that advantages those who can smoothly integrate awareness of cultural and religious as well as racial difference and, for whites, project a racial-self awareness and openness. Legal compliance comes through Michigan's relentless message that race is not the only or maybe even the most important aspect of diversity, and the applicants then amplify and refract that message. The differences that begin to take shape in our data between what conceptions of diversity occur to types of applicants suggest a persistent if vaguely defined binary. On the one hand, there is the classically race-focused account of diversity, in which being a racial or ethnic minority has a special status. People who are themselves minorities will more readily recognize this account of diversity, the theory goes, accept that it imposes a duty or desirable status upon them, and will not have to cast about for other ways to talk about diversity. On the other hand, if one is white, it is better to talk about diversity in terms that potentially include oneself, such as experiences abroad or encounters with religious difference. Diversity in international culture and religion are prominent nonracial axes of difference, and so it is not surprising that as diversity rhetoric loses its focus on race these categories would become more salient. Applicants who are minorities and also descended from immigrant families (mostly Latinos) then have the most obvious way to integrate these two conceptions. Native-born blacks are then left as the most racialized group that simultaneously lacks an outlet to the more cosmopolitan and trendy essay themes beyond race at the same time as they are the most likely to be marked as diversity candidates. We must acknowledge that much of these data counsel 
Table 2. Characterizations of Diversity by Race and Income Strata Within Matched Clusters

\begin{tabular}{|c|c|c|c|c|c|c|}
\hline & \multicolumn{2}{|c|}{ Low Income } & \multicolumn{2}{|c|}{ Middle Income } & \multicolumn{2}{|c|}{ High Income } \\
\hline & Whites & URMs & Whites & URMs & Whites & URMs \\
\hline Cultural diversity question & 0.60 & 0.47 & 0.50 & $0.86^{*}$ & 0.59 & 0.44 \\
\hline Individualistic question & 0.40 & 0.53 & 0.50 & $0.14^{*}$ & 0.41 & 0.56 \\
\hline Mentions diversity & 0.87 & 0.87 & 0.78 & 0.86 & 0.76 & 0.88 \\
\hline Race/ethnicity & 0.72 & $1.20^{+}$ & 0.60 & 0.66 & 0.41 & $0.83^{*}$ \\
\hline Class & 0.30 & 0.06 & 0.14 & 0.10 & 0.43 & 0.26 \\
\hline Religion & 0.44 & $0.09^{*}$ & 0.31 & 0.10 & 0.35 & 0.24 \\
\hline Culture & 0.56 & 0.57 & 0.31 & 0.67 & 0.33 & 0.66 \\
\hline Opinions/viewpoints & 0.11 & 0.06 & 0.00 & $0.33^{*}$ & 0.08 & 0.15 \\
\hline Internationalism & 0.14 & 0.00 & 0.07 & 0.00 & 0.26 & 0.06 \\
\hline Individual uniqueness & 0.18 & 0.06 & 0.20 & $0.00^{+}$ & 0.29 & 0.00 \\
\hline
\end{tabular}

Notes: ${ }^{+} p<0.10 ; * p<0.05 ; * * p<0.01 ; * * * p<0.001$.

against drawing strong inferences about how much difference one's race makes for how one sees diversity, since we have several null findings about race. Yet if there is a story here about the difference racial identity makes, we will suggest that it is something like this one.

Table 1 does not show the effects of the income strata of the high schools the applicants came from. What happens when we look at the same data but broken down by income in Table 2? In many ways, similarly situated applicants of different races wrote fairly similar essays, suggesting that their racial differences were not important enough to differentiate them in our analysis. But sometimes class position does seem to bring out racial variation. Middle-class minorities invoke diversity as opinions or viewpoints and do not mention race any more than their white classmates, while their lower-income and high-income counterparts do the opposite. It is the lower-income whites who write about religion much more than their minority counterparts. Minorities from all income strata have very low rates of linking diversity with internationalism.

What about the kinds of encounters with diversity that applicants described (see Table 3)? In the whole sample (remember, including more white students who would not be matched subsequently) it looks like minorities write more about arriving in a new place and playing sports as sites of encountering diversity, but once those minorities are matched with otherwise similar whites, their essays are indistinguishable on those points. Are there some kinds of experiences that provide great fodder for a diversity essay that are linked to class position (see Table 4)? Some differences by race fall out after matching, leaving only writing about the diversity of one's high school or one's immigrant family as racial differences.

The class-conscious results in Table 4 demonstrate that some of the most class-linked sites for encounter with diversity (travel and 
Table 3. Encounters With Diversity by Race of the Essay Writer

\begin{tabular}{|c|c|c|c|c|c|c|}
\hline & \multicolumn{3}{|c|}{ Unadjusted } & \multicolumn{3}{|c|}{ Matched } \\
\hline & Whites & URMs & diff. & Whites & URMs & diff. \\
\hline Travel/moving & 0.10 & 0.45 & $0.35^{*}$ & 0.38 & 0.39 & 0.00 \\
\hline Sports & 0.03 & 0.27 & $0.24 .^{+}$ & 0.17 & 0.19 & 0.02 \\
\hline Friendship & 0.21 & 0.18 & -0.03 & 0.30 & 0.17 & -0.13 \\
\hline In high school & 0.30 & 0.20 & -0.10 & 0.70 & 0.30 & $-0.40^{*}$ \\
\hline Summer program & 0.06 & 0.23 & 0.16 & 0.14 & 0.21 & 0.07 \\
\hline Immigrant family & 0.01 & 0.33 & $0.32^{*}$ & 0.04 & 0.23 & $0.19^{*}$ \\
\hline Bi-cultural parents & 0.04 & 0.19 & 0.14 & 0.09 & 0.22 & 0.13 \\
\hline
\end{tabular}

Notes: ${ }^{+} p<0.10 ; * p<0.05 ;{ }^{* *} p<0.01 ; * * * p<0.001$.

summer programs) do not differentiate by race very much. This could be due to coding for the theme of a new place, where moving to a new home is coded the same as travel and where summer programs could be both expensive camps or minority-focused enrichment, perhaps paid by scholarship. Affluent whites do write about travel experiences, but so do middle-income minority applicants. Invoking travel or moving is entirely absent from essays from lower-income minority writers. The attention to one's school as a site of encounter with diversity (or lack of it) turns out to be significantly a focus of lower-income whites.

Analysis of the essays for normative conclusions about diversity (see Table 5) shows the insights gained from matching most starkly. The unadjusted comparison looks right intuitively: Whites would begin by saying how not-diverse their environment was and how much they yearn to experience diversity, and they scatter in a few more platitudes about their stereotypes would be shattered by encountering it. They would not notice that diversity can mean racialized discomfort and can be useful as protection from discrimination, and that calls for diversity sound to minority students like invitations to come share oneself. Conversely, minority students would be more aware that they are the ones marked as diverse and that integration has tangible benefits, like not standing out as the only nonwhite person. There are many differences like

Table 4. Encounters With Diversity (matched comparison by race and income strata)

\begin{tabular}{lcccccccc}
\hline & \multicolumn{2}{c}{ Low Income } & & \multicolumn{2}{c}{ Middle Income } & & \multicolumn{2}{c}{ High Income } \\
\cline { 2 - 3 } & Whites & URMs & & Whites & URMs & & Whites & URMs \\
\hline Travel/moving & 0.12 & 0.00 & & 0.17 & $0.95^{*}$ & & 0.84 & 0.29 \\
Sports & 0.00 & 0.00 & & 0.32 & 0.65 & & 0.22 & 0.00 \\
Friendship & 0.06 & 0.06 & & $0.58^{+}$ & $0.17^{+}$ & & 0.30 & 0.29 \\
In high school & 1.13 & $0.46^{*}$ & & 0.49 & 0.09 & & 0.45 & 0.32 \\
Summer program & 0.06 & 0.43 & & 0.14 & 0.20 & & 0.24 & 0.00 \\
Immigrant family & 0.06 & 0.00 & & $0.07^{+}$ & $0.51^{+}$ & & 0.00 & 0.24 \\
Bi-cultural parents & 0.12 & 0.15 & & 0.10 & 0.27 & & 0.06 & 0.24 \\
\hline
\end{tabular}

Notes: ${ }^{+} p<0.10 ; * p<0.05 ; * * p<0.01 ; * * * p<0.001$. 
Table 5. Observations About Diversity by Race of the Essay Writer

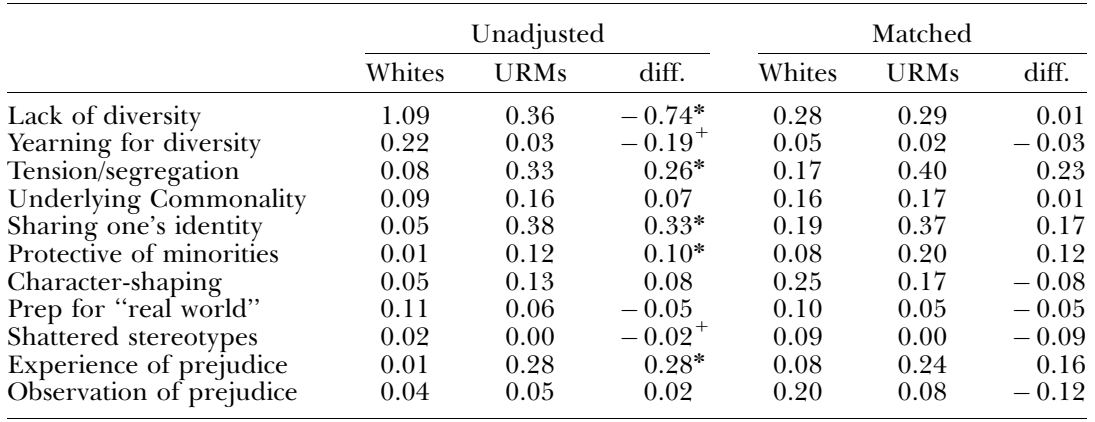

Notes: ${ }^{+} p<0.10 ;{ }^{*} p<0.05 ;{ }^{* *} p<0.01 ; * * * p<0.001$.

these in how whites and minorities draw conclusions about diversity. Just reading stacks of essays knowing the writer's race might lead to the conclusion that race is what explains these differences. But after comparing them to others who are similar in many ways except for race, all those differences fade into statistical nonsignificance.

Table 6 presents matched comparisons broken down by income level of the high school. The lower income strata is the site of the only significantly divergent observation about diversity: lower-income minority applicants notice diversity's tense and segregating features while their white counterparts, often in the very same school, do not write about it. One applicant described, for example, the "constant tension with all of the students aware of which hall is 'the black hall' or 'the Chaldean hall' or some other group's hall." Putnam's recent work (2007) has suggested that diverse environments cause "hunkering down" within communities, suggesting that segregating tendencies would be a natural observation to offer about diversity along with all the chirpy platitudes these essays invite. White and minority applicants from both middle- and upper-income situations invoke tense situations at almost identical rates, by contrast.

Table 6. Observations About Diversity (matched comparison by race and income)

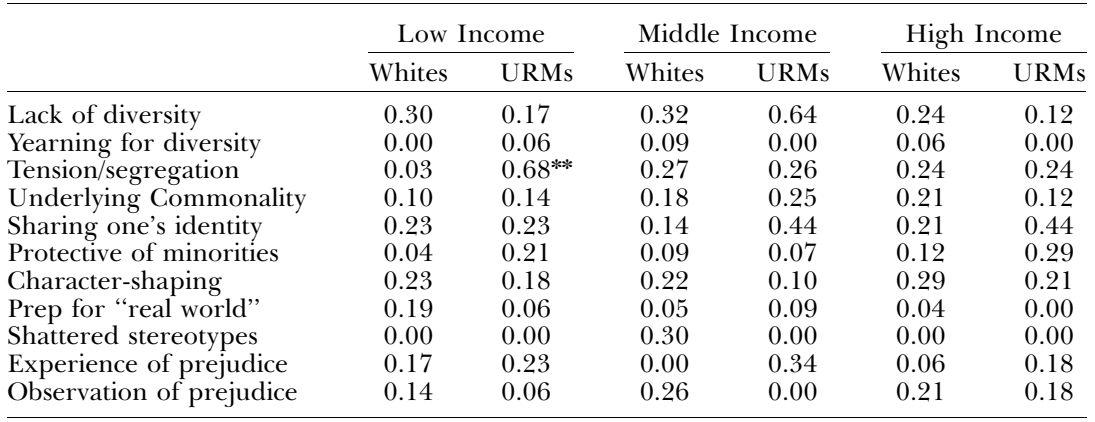

Notes: ${ }^{+} p<0.10, * p<0.05 ; * * p<0.01 ; * * * p<0.001$. 


\section{Conclusion}

Our study offers a multimethod view of an understudied moment in diversity politics and practices: the presentation of an applicant's required diversity essay. The postures applicants think are most effective here are extremely telling, and they give us a new angle for understanding how the University of Michigan's diversity strategies reflect back into the organization as applicants absorb and return their responses. One particular strength of our design is its ability to highlight close comparisons between essay writers on axes of race and class so that we can finally disaggregate those traits and determine if they make any difference in essay content. Our design has limitations as well, of course. It captures a relatively small sample at one moment in time and does not follow the essays all the way down their organizational path though the admissions process. These essays are very short and highly strategic, and confidentiality constraints prohibit us from finding out anything more about the essay writers such as how they experienced diversity in college. The focus group is thus disconnected from the essay sample, very small, and perhaps so unique that generalizations cannot be drawn from it. Future work could address these limitations by extending the view of the essay longer across time, perhaps beginning with the applicants' deciding what to write in the first place and following essays through the admissions process. Other sites and historical moments besides this admittedly critical yet unique one might also reveal institutional variation in diversity messaging and applicant reception. One benefit we had here was that the Michigan essay prompt did not refer to race or ethnicity (as nearly all the surveys in the scholarly literature seem to), and therefore we could see which topics were selected without that salient prompt. But the prompt did say "cultural diversity," so we were unable to tell what applicants might come up with if prompted to write about "diversity unmodified." If religion and cosmopolitan global culture are part of what "cultural" triggers as a modifier, then it would be important for future research to omit that prompt in order to test our conclusion that the diversity consensus has shifted toward these types of themes and away from minority racial and ethnic disadvantage.

What, given these limitations, can we nonetheless conclude from this analysis? Lipson's and Berrey's work establishes that there is a consensus about the appropriateness of diversity discourse at Michigan and that it has been carefully crafted over recent decades to send signals of legal compliance, brand desirability, and expansiveness. In many ways these essays demonstrate an enthusiastic reception of these messages. Some presumptions about what the diversity essay does are thus proven incorrect. Conservative commentators assumed at the time of Grutter and Gratz that 
the new diversity essay at Michigan was simply "the easiest way to maintain racial preferences within the new limits enunciated by the Court," as Wood (2003: n.p.) wrote in a National Review Online piece called "Imaginary Friends: How to Write a Diversity Essay" soon after the decisions (see also Graglia 2004). Wood's lampoon suggests the conventional wisdom from conservatives about what the diversity essay would do: serve as an easy way for minority students to signal their desirable status while demanding that whites recite some "diversity deep truths" such as the reality of prejudice in America (best told, according to Wood, as a small incident one witnessed happening to a friend named Muhammed or Jose) or the thrill of encountering difference.

These themes indeed occur regularly and vary somewhat by race in the whole sample, but the closer matched analysis belies Wood's characterization. Among applicants who are otherwise similar, there is no greater tendency to announce oneself racially among minorities than whites. Wood (2003: n.p.) tells applicants that "[t]he dramatic moment you will need to work for is the shining realization that we are all diverse," a characterization best captured by the "individual uniqueness" theme (emphasis in original). Whites do indeed invoke this theme more than their minority counterparts, but overall it would seem that conservative commentators do not have their fingers to the pulses of diversity essay writers. They are missing all the ways that the new diversity rhetoric is exactly what they would have wanted: de-racialized and individualistic. They do not yet realize that they have already won in the sense that the next generation does not seem to link race and diversity necessarily. Conservatives suspect admissions officials of trying to sneak race quotas in the back door, but our data suggest that even if that were true, the diversity essay is not a very good tool for achieving it. If critics like Wood want to both curry favor with admissions officials and move diversity rhetoric away from any connection to race-based affirmative action, they would do better to suggest an essay about the desire to understand international cultural or religious differences. These themes are already widely endorsed as suitable topics in both the coaching literature and in ordinary applicants' minds.

In an interesting twist, critics of diversity are allied with our lower-income minority essayists, who emerge as the primary source of critical perspectives on diversity. These applicants see what a crude racial representationalism produces: the clique-y-ness, the tension, the segregation that nonetheless persists. Perhaps, as we speculated at the start of this project, these applicants' parents did not attend corporate diversity training and so their children have less opportunity to learn how to talk the diversity talk. The organization here puts out a specific prompt and has a highly evolved 
organizational culture ready and waiting for a set of responses that are now also widely understood. But because Michigan casts such a wide net, some applicants are more outside diversity culture than others. The essay advantages someone with an international angle (maybe through a parent's heritage or immigrant family members) who can craft an essay that is about reaching out for difference, stretching, and being challenged (but not too much). Those who have only the tedious tension of lower-income segregated American life to write about will fall further outside the corporate/ educational diversity loop. Then the question becomes how to confront the possibility that the essay itself has reinforced a great deal of crude racial representationalism ("war movie" diversity) and vacuous individualism ("snowflake" diversity), and may leave lower-income minority students feeling like they somehow missed the point but ought not to share their more critical perspective in light of the cheery diversity consensus. The diversity essay is itself a meter of privilege that does not map exactly onto the usual race and class dimensions, but it nonetheless creates a hierarchy of stories and experiences that are more accessible to some young people than others. 
Appendix Table A. Themes by Minority Group Compared to White Applicants

\begin{tabular}{|c|c|c|c|c|c|c|}
\hline & Whites & Asians & diff. & Whites & URM & diff. \\
\hline Cultural diversity question & 0.44 & 0.40 & -0.44 & 0.44 & 0.58 & 0.14 \\
\hline Individualistic question & 0.56 & 0.60 & 0.04 & 0.56 & 0.42 & -0.14 \\
\hline Mentions diversity & 0.61 & 0.94 & $0.33^{* * * *}$ & 0.61 & 0.78 & 0.17 \\
\hline Race/ethnicity & 0.22 & 0.47 & 0.25 & 0.22 & 0.77 & $0.55^{* * * * *}$ \\
\hline Gender & 0.07 & 0.00 & -0.07 & 0.07 & 0.02 & -0.06 \\
\hline Class & 0.06 & 0.02 & -0.04 & 0.06 & 0.09 & 0.03 \\
\hline Religion & 0.14 & 0.13 & -0.01 & 0.14 & 0.09 & -0.06 \\
\hline Culture & 0.18 & 0.74 & $0.56^{* * * *}$ & 0.18 & 0.53 & $0.34^{* *}$ \\
\hline Disability & 0.02 & 0.00 & -0.02 & 0.02 & 0.01 & -0.02 \\
\hline Sexual orientation & 0.01 & 0.00 & $-0.01^{*}$ & 0.01 & 0.01 & 0.00 \\
\hline Music and food & 0.08 & 0.08 & 0.01 & 0.08 & 0.10 & 0.02 \\
\hline Experience of prejudice & 0.01 & 0.06 & 0.05 & 0.01 & 0.28 & $0.28^{*}$ \\
\hline Observation of prejudice & 0.04 & 0.01 & -0.03 & 0.04 & 0.05 & 0.02 \\
\hline Opinions and viewpoints & 0.13 & 0.22 & 0.09 & 0.13 & 0.17 & 0.04 \\
\hline Internationalism & 0.33 & 0.95 & 0.62 & 0.33 & 0.01 & $-0.32^{+}$ \\
\hline Exchange students & 0.21 & 0.00 & -0.21 & 0.21 & 0.07 & -0.14 \\
\hline Individual uniqueness & 0.04 & 0.00 & $-0.04^{*}$ & 0.04 & 0.03 & -0.01 \\
\hline Sharing one's identity & 0.05 & 1.44 & $1.39^{+}$ & 0.05 & 0.38 & $0.33^{*}$ \\
\hline Protective of minorities & 0.01 & 0.05 & 0.03 & 0.01 & 0.12 & $0.10^{*}$ \\
\hline Character-shaping & 0.05 & 0.16 & 0.11 & 0.05 & 0.13 & 0.08 \\
\hline Prep for "real world" & 0.11 & 0.01 & -0.10 & 0.11 & 0.06 & -0.05 \\
\hline Shattered stereotypes & 0.02 & 0.00 & $-0.02^{+}$ & 0.02 & 0.00 & $-0.02^{+}$ \\
\hline Small town & 0.03 & 0.00 & -0.03 & 0.03 & 0.00 & -0.03 \\
\hline Travel or moving & 0.10 & 0.60 & 0.50 & 0.10 & 0.45 & $0.35^{*}$ \\
\hline Sports & 0.03 & 0.00 & $-0.03^{+}$ & 0.03 & 0.27 & $0.24^{+}$ \\
\hline Friendship & 0.21 & 0.00 & $-0.21^{*}$ & 0.21 & 0.18 & -0.03 \\
\hline High school & 0.30 & 0.24 & -0.05 & 0.30 & 0.20 & -0.10 \\
\hline Hometown & 0.03 & 0.12 & 0.09 & 0.03 & 0.05 & 0.01 \\
\hline Workplace & 0.01 & 0.03 & 0.02 & 0.01 & 0.05 & 0.05 \\
\hline Volunteering & 0.10 & 0.02 & -0.08 & 0.10 & 0.07 & -0.03 \\
\hline Summer program & 0.06 & 0.00 & -0.06 & 0.06 & 0.23 & 0.16 \\
\hline Immigrant family & 0.01 & 0.57 & $0.57^{+}$ & 0.01 & 0.33 & $0.32 *$ \\
\hline Bi-cultural parents & 0.04 & 0.00 & -0.04 & 0.04 & 0.19 & 0.14 \\
\hline Books or studying & 0.04 & 0.00 & -0.04 & 0.04 & 0.01 & -0.02 \\
\hline Lack of diversity & 1.09 & 0.11 & $-0.98^{* * * *}$ & 1.09 & 0.36 & $-0.74^{*}$ \\
\hline Yearning for diversity & 0.22 & 0.22 & -0.01 & 0.22 & 0.03 & $-0.19^{+}$ \\
\hline Sham efforts & 0.00 & 0.00 & 0.00 & 0.00 & 0.05 & 0.05 \\
\hline Tension/segregation & 0.08 & 0.06 & -0.02 & 0.08 & 0.33 & $0.26^{*}$ \\
\hline Underlying commonality & 0.09 & 0.03 & -0.06 & 0.09 & 0.16 & 0.07 \\
\hline
\end{tabular}

Notes: ${ }^{+} p<0.10 ; * p<0.05 ; * * p<0.01 ; * * * p<0.001$.

Appendix Table B. Effects of Matching

\begin{tabular}{lrrrrrr}
\hline & Whites & URMs & diff. & Whites & URMs & \multicolumn{1}{c}{ diff. } \\
\hline Women & 0.49 & 0.48 & -0.01 & 0.4 & 0.51 & 0.11 \\
Men & 0.51 & 0.52 & 0.01 & 0.6 & 0.49 & -0.11 \\
In-state & 0.39 & 0.32 & -0.06 & 0.39 & 0.37 & -0.02 \\
High school & 0.01 & 0.15 & $0.14^{* *}$ & 0.09 & 0.06 & -0.02 \\
Diploma or less & & & & & & \\
Some college & 0.24 & 0.26 & 0.02 & 0.06 & 0.21 & $0.15^{*}$ \\
College degree & 0.21 & 0.26 & 0.05 & 0.2 & 0.3 & 0.1 \\
Advanced degree & 0.46 & 0.3 & -0.16 & 0.57 & 0.37 & $-0.2^{*}$ \\
Income unknown & 0.24 & 0.17 & -0.07 & 0.16 & 0.22 & 0.06 \\
25K-50K & 0.07 & 0.21 & 0.14 & 0.07 & 0.16 & 0.09 \\
50K-75K & 0.18 & 0.04 & -0.15 & 0.1 & 0.04 & -0.06 \\
75K-100K & 0.1 & 0.05 & -0.06 & 0.14 & 0.03 & $-0.11^{+}$ \\
Less than 25K & 0.01 & 0.19 & $0.18^{* * *}$ & 0.03 & 0.16 & $0.13^{*}$ \\
More than 100K & 0.29 & 0.23 & -0.06 & 0.38 & 0.29 & -0.1 \\
"Don't know" income & 0.1 & 0.12 & 0.01 & 0.11 & 0.1 & -0.01 \\
Married parents & 0.76 & 0.61 & -0.15 & 0.76 & 0.56 & $-0.19^{*}$
\end{tabular}


Appendix Table B. Continued

\begin{tabular}{lcccrrr}
\hline & Whites & URMs & diff. & Whites & URMs & diff. \\
\hline Single parent & 0.18 & 0.32 & 0.14 & 0.21 & 0.35 & 0.14 \\
MI high school & 0.53 & 0.47 & -0.07 & 0.52 & 0.47 & -0.05 \\
Number taking ACT & 144 & 142.8 & -1.25 & 115.2 & 128.49 & 13.33 \\
Average ACT score & 23.65 & 22.76 & $-0.89^{*}$ & 23.8 & 23.51 & -0.29 \\
Number taking SAT & 121.29 & 162.1 & 40.8 & 152.7 & 162.96 & 10.26 \\
Average SAT math score & 594.19 & 568.1 & $-26.14^{*}$ & 597.01 & 586.67 & -10.34 \\
Average SAT verbal score & 582.38 & 559.9 & $-22.47^{+}$ & 590.35 & 581.54 & -8.81 \\
Men taking SAT & 60.31 & 77.43 & 17.12 & 75.29 & 78.63 & 3.35 \\
Women taking SAT & 60.97 & 84.65 & 23.68 & 77.42 & 84.33 & 6.91 \\
Median income ACT takers & $63 \mathrm{~K}$ & $57 \mathrm{~K}$ & $-6 \mathrm{~K}$ & $62 \mathrm{~K}$ & $63 \mathrm{~K}$ & $1 \mathrm{~K}$ \\
Income of 25th & $43 \mathrm{~K}$ & $37 \mathrm{~K}$ & $-6 \mathrm{~K}^{* *}$ & $45 \mathrm{~K}$ & $44 \mathrm{~K}$ & $-1 \mathrm{~K}$ \\
percentile ACT takers & & & & & & \\
Median income SAT takers & $69 \mathrm{~K}$ & $60 \mathrm{~K}$ & $-9 \mathrm{~K}^{*}$ & $65 \mathrm{~K}$ & $64 \mathrm{~K}$ & $-1 \mathrm{~K}$ \\
Income of 25th & $55 \mathrm{~K}$ & $44 \mathrm{~K}$ & $-11 \mathrm{~K}^{* *}$ & $53 \mathrm{~K}$ & $52 \mathrm{~K}$ & $-1 \mathrm{~K}$ \\
Percentile SAT takers & & & & & & \\
Private school & 0.08 & 0.1 & 0.02 & 0.27 & 0.24 & -0.03 \\
Public school & 0.82 & 0.67 & $-0.14^{*}$ & 0.55 & 0.55 & 0.01 \\
Religious school & 0.07 & 0.18 & $0.11^{+}$ & 0.12 & 0.16 & 0.04 \\
Large city & 0.17 & 0.43 & $0.26^{* * *}$ & 0.36 & 0.45 & 0.09 \\
Medium city & 0.09 & 0.06 & -0.03 & 0.09 & 0.04 & -0.05 \\
Location unknown & 0.02 & 0.05 & 0.03 & 0.06 & 0.05 & -0.01 \\
Rural & 0.31 & 0.21 & -0.1 & 0.27 & 0.23 & -0.03 \\
Suburban & 0.19 & 0.18 & -0.01 & 0.18 & 0.17 & -0.01 \\
Town & 0.22 & 0.08 & -0.14 & 0.04 & 0.06 & 0.02 \\
\hline
\end{tabular}

Notes: ${ }^{+} p<0.10 ; * p<0.05 ; * * p<0.01 ; * * * p<0.001$.

\section{References}

Bell, Joyce M., \& Douglas Hartmann (2007) "Diversity in Everyday Discourse: The Cultural Ambiguities and Consequences of Happy Talk," 72 American Sociological Rev. 895-914.

Berrey, Ellen C. (2009) Inclusion for All: "Diversity" And the Meaning of Racial Equality in Post-Civil Rights America. Unpublished manuscript.

- (forthcoming) "Why Diversity Became Orthodox in Higher Education, and How It Changed the Meaning of Race on Campus," Critical Sociology, forthcoming.

Bodine, Paul (2006) Great Application Essays for Business School. New York: McGraw-Hill.

Boli, John, \& Michael A. Elliott (2008) "Facade Diversity: The Individualization of Cultural Difference," 23 International Sociology 540-60.

Campbell, David E. (2007) "Sticking Together: Classroom Diversity and Civic Education," 35 American Politics Research 57-78.

Carbado, Devon W., \& Cheryl I. Harris (2008) "The New Racial Preferences," 96 California Law Rev. 1139-214.

College Confidential (2008) "College Confidential," http://talk.collegeconfidential.com/ college-essays/463195-uh-how-do-i-bring-diversity.html?highlight=diversity $\quad$ (accessed 6 Dec. 2010).

Denson, Nida (2009) "Do Curricular and Cocurricular Diversity Activities Influence Racial Bias? A Meta-Analysis," 79 Rev. of Educational Research 805-38.

Edelman, Lauren B. (1992) "Legal Ambiguity and Symbolic Structures: Organizational Mediation of Civil Rights Law," 97 American J. of Sociology 1531-76.

(2005) "The Endogeneity of Law: Civil Rights at Work," in R. L. Nelson \& L. B. Nielsen, eds., Handbook on Employment Discrimination Research: Rights and Realities. Dordrecht, the Netherlands: Kluwer Academic Press.

Edelman, Lauren B., Howard S. Erlanger, et al. (1993) "Internal Dispute Resolution: The Transformation of Civil Rights in the Workplace," 27 Law \& Society Rev. 497-534. 
Edelman, Lauren B., Sally Riggs Fuller, et al. (2001) "Diversity Rhetoric and the Managerialization of Law," 106 American J. of Sociology 589-641.

Graglia, Lino A. (2004) "Grutter and Gratz: Race Preference to Increase Racial Representation Held 'Patently Unconstitutional' Unless Done Subtly Enough in the Name of Pursuing 'Diversity,"' 78 Tulane Law Rev. 2037-53.

Gurin, Patricia, Eric L. Dey, et al. (2003) "How Does Racial/Ethnic Diversity Promote Education?" 27 Western J. of Black Studies 20-9.

Gurin, Patricia, Jeffrey S. Lehman, et al. (2004a) Defending Diversity: Affirmative Action at the University of Michigan. Ann Arbor: Univ. of Michigan Press.

Gurin, Patricia, Biren A. Nagda, et al. (2004b) "The Benefits of Diversity in Education for Democratic Citizenship," $60 \mathrm{~J}$. of Social Issues 17-34.

Hansen, Ben B., \& Stephanie O. Klopfer (2006) "Optimal Full Matching and Related Designs Via Network Flows," $15 \mathrm{~J}$. of Computational and Graphical Statistics 609-27.

Horowitz, David (2004) "In Defense of Intellectual Diversity," The Chronicle of Higher Education B12 (February 13).

Hurtado, Sylvia, et al. (2003) "College Environments, Diversity, and Student Learning," 18 Higher Education: Handbook of Theory and Research 145-90.

Kalev, Alexandra, et al. (2006) "Best Practices or Best Guesses? Diversity Management and the Remediation of Inequality," 71 American Sociological Rev. 589-617.

Karabel, Jerome (2005) The Chosen: The Hidden History of Admission and Exclusion at Harvard, Yale, and Princeton. New York: Houghton Mifflin Harcourt.

Kelly, Erin, \& Frank Dobbin (1998) "How Affirmative Action Became Diversity Management: Employer Response to Antidiscrimination Law, 1961 to 1996," 41 American Behavioral Scientist 960-84.

Kirkland, Anna (2008) Fat Rights: Dilemmas of Difference and Personhood. New York: New York Univ. Press.

Kramer, Stephen, \& Michael London (2006) The New Rules of College Admissions: Ten Former Admissions Officers Reveal What It Takes to Get into College Today. New York: Fireside.

Lipson, Daniel N. (2007) "Embracing Diversity: The Institutionalization of Affirmative Action as Diversity Management at UC-Berkeley, UT-Austin, and UW-Madison," 32 Law and Social Inquiry 985-1026.

Mason, Michael James (2000) How to Write a Winning College Application Essay. New York: Three Rivers Press.

Oliver, J. Eric (2001) Democracy in Suburbia. Princeton, NJ: Princeton Univ. Press.

Pascarella, Ernest T., et al. (1996) "Influences on Students' Openness to Diversity and Challenge in the First Year of College," 67 J. of Higher Education 174-95.

Peterson, Julie (2003) "New U-M Undergraduate Admissions Process to Involve More Information, Individual Review," University of Michigan News Service, http://www. umich.edu/news/index.html?Releases/2003/Aug03/admissions (accessed 11 Jan. 2010).

Putnam, Robert D. (2007) "E Pluribus Unum: Diversity and Community in the TwentyFirst Century," 30 Scandinavian Political Studies 137-74.

Reinisch, June Machover, et al. (1995) "In Utero Exposure to Phenobarbital and Intelligence Deficits in Adult Men," 274 J. of the American Medical Association 1518-25.

Rosenbaum, Paul R. (1991) "A Characterization of Optimal Designs for Observational Studies," $53 \mathrm{~J}$. of the Royal Statistical Society 597-610.

Rosenbaum, Paul R., \& Donald B. Rubin (1983) "The Central Role of the Propensity Score in Observational Studies for Causal Effects," 70 Biometrika 41-55.

- (1985) "Constructing a Control Group Using Multivariate Matched Sampling Methods That Incorporate the Propensity Score," 39 American Statistician 33-8.

Santos, Silvia J., et al. (2007) "The Relationship Between Campus Diversity, Students' Ethnic Identity and College Adjustment: A Qualitative Study," 13 Cultural Diversity and Ethnic Minority Psychology 104-14. 
Steinberg, Jacques (2003) The Gatekeepers: Inside the Admissions Process of a Premier College. New York: Penguin.

Stevens, Mitchell L. (2007) Creating a Class: College Admissions and the Education of Elites. Cambridge, MA: Harvard Univ. Press.

Trzesniewski, Kali, et al. (2008) “Do Today's Young People Really Think They Are So Extraordinary? An Examination of Secular Trends in Narcissism and SelfEnhancement," 19 Psychological Science 181-8.

Twenge, Jean M. (2006) Generation Me: Why Today's Young Americans Are More Confident, Assertive, Entitled-and More Miserable Than Ever Before. New York: Free Press.

Wood, Peter W. (2003) "Imaginary Friends: How to Write the Diversity Essay," National Review Online, September, http://old.nationalreview.com/comment/wood20030930 0825.asp (accessed 6 Dec. 2010).

\section{Statute Cited}

Constitution of Michigan, Article 1, § 26 (Michigan Civil Rights Initiative), approved 7 Nov. 2006, eff. 23 Dec. 2006.

\section{Cases Cited}

Gratz v. Bollinger, 539 U.S. 244 (2003).

Grutter v. Bollinger, 539 U.S. 306 (2003).

Regents of the University of California v. Bakke, 438 U.S. 265 (1978).

Anna Kirkland is Associate Professor of Women's Studies and Political Science at the University of Michigan. She is the author of Fat Rights: Dilemmas of Difference and Personhood (NYU Press, 2008) and a co-editor of Against Health: Has Health Become the New Morality? (NYU Press, 2010) as well as articles on legal consciousness, transgender rights, disability, and the environmental account of obesity. During the 2010-2011 academic year, Kirkland is a Law and Public Affairs Fellow at Princeton University, where she is writing a book on vaccine injury litigation, regulatory politics, and citizen activism.

Ben B. Hansen is Associate Professor of Statistics at the University of Michigan. His research interests center on causal inference for comparative studies, including randomization-based inference, optimal matching, propensity scores and related techniques, and applications of these methods to education, political science, and the social sciences broadly. He is a co-developer of "optmatch" and "RItools," modules for the R statistical package for optimal matching and for randomization-based inference. His research publications appear in journals such as the Annals of Applied Statistics, Biometrika, Social Science and Medicine, and the Journal of the American Statistical Association. 